\title{
CONCENTRAÇÃO DE FÓSFORO PRESENTE NOS RECURSOS HÍDRICOS: AVALIAÇÃO DO ÍNDICE DE ESTADO TRÓFICO DO BALNEÁRIO DE QUATÁ-SP
}

\section{CONCENTRATION OF PHOSPHORUS PRESENT IN WATER RESOURCES: EVALUATION OF THE TROPHIC STATE INDEX OF MUNICIPAL SPA OF QUATA- SP}

\author{
Jaine D’Aurelio Carreira ; Daniel Ângelo Macena ${ }^{2}$; Jaqueline Nascimento da \\ Silva ${ }^{3}$ \\ ${ }^{1}$ Universidade do Oeste Paulista - UNOESTE, Faculdade de Ciências, Letras e Educação \\ de Presidente Prudente - FACLEPP \\ E-mail: jainne._@hotmail.com ${ }^{1}$; daniel@unoeste.br ${ }^{2}$; jaqueline@unoeste.br ${ }^{3}$
}

RESUMO - A água pode sofrer alterações físico-químicas naturais, porém muitas vezes é causada pela ação antrópica, devido ao descarte de efluente de forma incorreta. Tais alterações originam a eutrofização, que tem como consequência o alto índice de nutrientes como o fósforo e nitrogênio, levando ao crescimento da vegetação. Outras consequências podem ser a mortalidade de peixes, água de coloração escura da água, odor forte e a transferência de patógenos, que coloca em risco a saúde populacional. O presente trabalho teve como objetivo realizar análises de fósforo total no Balneário Municipal de Quatá-SP. O método utilizado para as análises foi de Fósforo com Reativo Ortofosfato, adaptado do Standard Methods for the Examination of Water and Wastewater e os resultados foram comparados com as classes de estado trófico e os parâmetros da legislação. Ao final das análises os valores obtidos de IET foram considerados altos, comprometendo a qualidade da água em alguns pontos.

Palavras-chave:Água; Nutrientes; Fósforo; Eutrofização; Legislação.

ABSTRACT - Water can undergo natural physico-chemical changes, but it is often caused by anthropogenic action due to improper disposal of effluent. These changes lead to eutrophication, which results in a high index of nutrients such as phosphorus and nitrogen, leading to vegetation growth. Other consequences may be fish mortality, dark water color of water, strong odor and transfer of pathogens, which endangers population health. The present work had as objective to perform analyzes of total phosphorus in the Municipal Spa of Quatá-SP. The method used for the analyzes was Phosphorus with Reactive Orthophosphate, adapted from the Standard Methods for the Examination of Water and Wastewater and the results were compared with the trophic state classes and the parameters of the legislation. At the end of the analyzes, the values obtained from EIT were considered high, compromising the quality of the water in some points.

Keywords: Water; Nutrients; Phosphorus; Eutrophication; Legislation. 


\section{INTRODUÇÃO}

Segundo Donadio, Galbiatti e Paula (2005) pode-se determinar a qualidade da água baseando-se na aplicação de variáveis que podem se comparar com as alterações ocorridas nos locais de origem da água, independentemente se essas mudanças sejam de origens antropológicas ou naturais.

Nutrientes são de extrema importância em uma cadeia alimentar, porém em excesso pode causar mudanças nas bacias hidrográficas. Com o crescimento populacional houve 0 aumento no lançamento de esgoto doméstico que são fontes de matérias orgânicas, tornandose um dos maiores agentes na abundância de tais nutrientes. Outros fatores que podem gerar mudanças são os fertilizantes e pesticidas agrícolas ricos em sais minerais (NETO; FERREIRA, 2007).

O transporte de poluentes ocorre pelo escoamento tanto superficiais quanto subsuperficiais das águas da chuva e outros meios que possam transportar resíduos, como, nutrientes, lixo e vários outros impasses existentes no caminho, ocasionando desequilíbrio no meio aquático. As alterações decorrentes de tais desequilíbrios podem ser avaliadas pelo monitoramento da qualidade da água (HADLICH; SCHEIBE, 2012).

Alguns padrões físico-químicos de qualidade da água podem-se aferir por análises de potencial hidrogeniônico $(\mathrm{pH})$, turbidez, demanda bioquímica de oxigênio (DBO), sólidos em suspensão, nitrogênio, fósforo total, entre outros. Sendo esses parâmetros capazes de mostrar as transformações existentes na biota aquática (PIVELI; KATO, 2006).

Especificamente, essas análises que determinam a qualidade da água podem ser realizadas de um modo geral, sendo físicos, químicos, biológicos ou até mesmo pela presença de poluentes e altas concentrações de nutrientes (fósforo e nitrogênio), pois contribuem significativamente no processo de eutrofização. Podendo também ser sinais de poluição orgânica (ESTEVES, 1988; SILVA et al., 2011).

Segundo Smith e Schindler (2009) a alta concentração desses nutrientes normalmente se dá em locais que possui comprometimento no fluxo da água, provocando fortes odores, diminuindo o oxigênio dissolvido, assim reduzindo espécies de peixes, e modificando a Colloquium Exactarum, vol. 10, n. Especial, Jul-Dez, 2018, p. 24- 28. ISSN: 2178-8332. DOI: 10.5747/ce.2018.v10.nesp.000152 vegetação existente. Essas características podem ser chamadas de Eutrofização ou Índice de Estado Trófico (IET).

O grande crescimento da vegetação como algas ou macrófitas aquáticas está relacionado à presença desses nutrientes. Com base na produtividade e qualidade do corpo hídrico foram pactuados parâmetros, onde dispõem limitações. Sendo assim, pode-se classificar um recurso hídrico a partir dos valores de fósforo disponível, onde, o índice de estado trófico avalia a qualidade da água em dissemelhantes graus de trofia. Os resultados do índice calculados a partir dos valores de fósforo, devem ser entendidos como uma medida do potencial de eutrofização, já que este nutriente atua como o agente causador do processo (CETESB, 2013).

O objetivo do trabalho foi avaliar o Índice de Estado Trófico a partir de resultados de fósforo disponível presentes em amostras de água coletadas no Balneário pertencente ao município de Quatá-SP.

\section{MATERIAL E MÉTODOS}

Foram 3 coletas amostrais entre os meses de setembro/2017 a março/2018. As amostras foram coletadas no terceiro domingo do mês, totalizando 18 amostras de 6 pontos diferentes do reservatório. As amostras foram corrigidas para $\mathrm{pH} 2$ com ácido clorídrico $1 \mathrm{M}$ no momento da coleta e reservada em geladeira para preservação físico-química das amostras.

A Figura 1 apresenta os pontos de coleta, onde ponto 1 é destinado ao público, na qual o ambiente fica aberto com quiosques, lanchonetes e demais materiais para lazer, e os demais pontos são destinados a propriedades privadas.

A determinação do Fósforo foi realizada pelo método de fósforo com reativo ortofosfato, adaptado do Standard Methods for the Examination of Water and Wastewater (APHA, 2005). 
Figura 1. Pontos de coleta no Balneário de QuatáSP

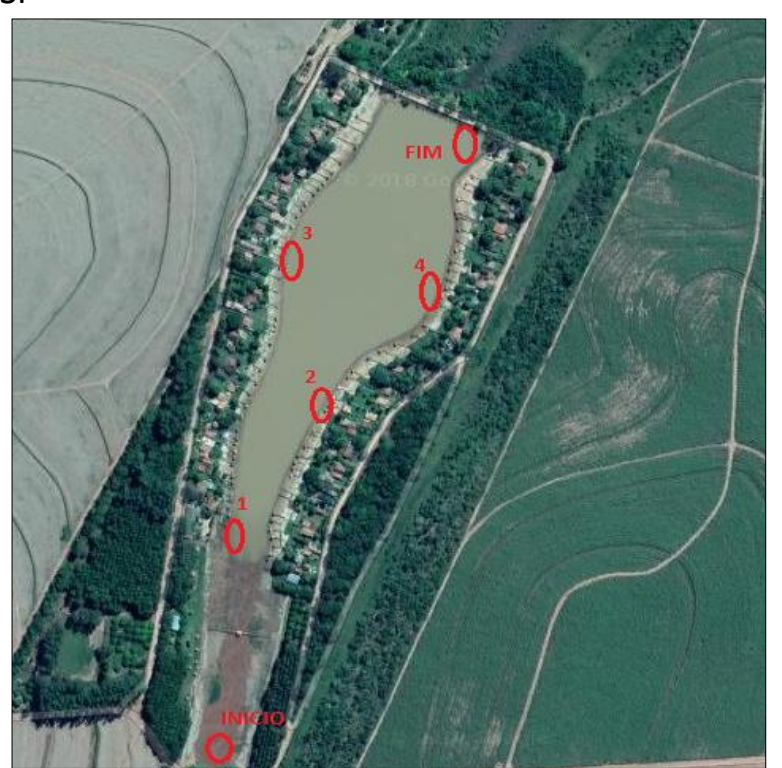

Fonte: Google Earth

Antes da leitura da concentração de fósforo cada amostra foi digerida a partir de uma alíquota de $25 \mathrm{~mL}$ de cada amostra que foi transferida para um becker, em seguida, foi adicionada $5 \mathrm{~mL}$ de solução de persulfato de potássio, e agitado. Posteriormente, o becker foi aquecido em chapa de aquecimento a $200{ }^{\circ} \mathrm{C}$, por 30 minutos. Nesta etapa o volume da solução foi mantido por volta de $20 \mathrm{~mL}$, adicionando água destilada sem que excedesse. Após a digestão, a amostra foi resfriada naturalmente, para posterior adição de $2 \mathrm{~mL}$ de solução de hidróxido de sódio $5 \mathrm{~N}$ e agitação da amostra.

A amostra foi transferida para um balão volumétrico de $25 \mathrm{~mL}$ e completado o volume até o menisco. E por fim, realizou-se a leitura para fosfato utilizando kit de teste da marca Hach para análises de fósforo, como ortofosfatos, modelo
PO-19A. Para a obtenção do teor de fósforo total os resultados da leitura do aparelho foram multiplicados pelo fator de correção 0,326.

O IET dos diversos pontos coletados do Balneário de Quatá foi calculado de acordo com a equação abaixo recomendado por Toledo Jr (1990).

IET $(P T)=10 \times(6-(1,77-0,42 \times(\ln P T)))$ $\ln 2$

PT: concentração de fósforo total medida à superfície da água, em $\mu g . L-1 ;$

In: logaritmo natural;

IET (PT): Índice de Estado Trófico para Fósforo.

Na tabela 1, baseada na concentração de fósforo total, pode-se observar e comparar a classificação trófica da amostra e a faixa de variação do IET.

Tabela 1. Critérios para classificação do índice de estado trófico (IET)

\begin{tabular}{cc}
\hline \hline Estado trófico & $\begin{array}{c}\text { Critério } \\
\text { (Índice de Estado Trófico) }\end{array}$ \\
\hline Ultraoligotrófico & $\mathrm{IET} \leq 47$ \\
Oligotrófico & $47<\mathrm{IET} \leq 52$ \\
Mesotrófico & $52<\mathrm{IET} \leq 59$ \\
Eutrófico & $59<\mathrm{IET} \leq 63$ \\
Supereutrófico & $63<\mathrm{IET} \leq 67$ \\
Hipereutrófico & $\mathrm{IET}>67$ \\
\hline \hline
\end{tabular}

Fonte: Carlson (1997) modificado por Toledo Jr (1990) 


\section{RESULTADOS E DISCUSSÃO}

Tabela 2. Índice de estado trófico para fósforo das amostras coletadas

\begin{tabular}{cccccc}
\hline \multirow{2}{*}{\begin{tabular}{c} 
Pontos de $\begin{array}{c}\text { Ioleta } \\
\text { Amostras }\end{array}$ \\
\cline { 2 - 4 }
\end{tabular}} & Coleta 1 & Coleta 2 & Coleta 3 & $\sum M_{I E T}$ & \multicolumn{5}{c}{ Índice de Estado Trófico para Fósforo } & Classificação \\
\cline { 2 - 4 } & $\mathrm{M}_{\mathrm{IET}}$ & $\mathrm{M}_{\mathrm{IET}}$ & $\mathrm{M}_{\mathrm{IET}}$ & $\frac{5}{3} \pm D$ & \\
\hline Ínicio & 62,77 & 63,41 & 64,51 & $63,56 \pm 0,9$ & Supereutrófico \\
$\mathbf{1}$ & 63,41 & 62,06 & 77,18 & $67,55 \pm 8,4$ & Hipereutrófico \\
$\mathbf{3}$ & 61,25 & 62,06 & 66,97 & $63,43 \pm 3,1$ & Supereutrófico \\
$\mathbf{3}$ & 63,99 & 65,00 & 67,61 & $65,53 \pm 1,9$ & Supereutrófico \\
$\mathbf{4}$ & 62,06 & 60,31 & 66,97 & $63,11 \pm 3,5$ & Supereutrófico \\
Fim & 62,06 & 59,21 & 67,61 & $62,96 \pm 4,3$ & Eutrófico \\
\hline
\end{tabular}

Fonte: Próprio autor

Ao observar os resultados das amostras (Tabela 2), percebe-se que a concentração de fósforo total disponível influencia diretamente no IET. Desta forma, comparando as três diferentes coletas, a última foi a que, $100 \%$ das amostras, apresentaram resultados maiores do que os outros períodos de análise. Apesar de entre os resultados, dentre cada coleta não terem apresentado tanta variação, um outro ponto que chama a atenção foi no resultado do ponto $1 \mathrm{da}$ terceira coleta, que apresentou resultado bem diferente até mesmo dos outros pontos desta mesma coleta.

Segundo a Agência Nacional das Águas (2014), a fim de controle e licenciamento ambiental o monitoramento de represas, lagos e reservatórios são muito utilizados a partir do IET e indicadores de qualidade da água. Isto explica o motivo deste estudo em utilizar três diferentes períodos de coleta, já que o balneário é utilizado principalmente para recreação, o que possivelmente pode implicar diretamente na qualidade do meio hídrico quando em período de maior frequência pelo público ou mudanças climáticas.

Observando as médias gerais e desvio padrão, é possível perceber o auto grau de trofia que ocorre no reservatório de Quatá. Embora, não haver relatos de dados pluviométricos neste estudo, é possível perceber nos resultados, altos valores na terceira coleta, principalmente no ponto 1 onde foi um período que houve momentos de grandes precipitações. 0 ponto 1 está localizado na área destinada ao público, isso explica o alto valor do IET, que normalmente em um balneário são os pontos mais difíceis de se obter um controle do que e de que maneira está sendo descartado e/ou utilizado pelos usuários. Desta forma, em período de precipitação ocorre alto escoamento superficial onde influencia no volume de água que acontece pela baixa cobertura florestal local.

De maneira geral, quanto ao estado de trofia do reservatório de Quatá, tende em períodos comuns manter-se quase que todo em estado supereutrófico. Segundo Lamparelli (2004) e a Cetesb (2007) os corpos d'água que se apresentam em estado supereutrófico tem como características alta produtividade em comparação às condições naturais, baixa transparência, normalmente ocorrem alterações indesejáveis na qualidade da água decorrente de atividades antrópicas e interferentes nos seus diferentes usos.

\section{CONSIDERAÇÕES FINAIS}

A utilização do IET é uma maneira eficiente como ferramenta para o monitoramento ambiental da qualidade da água, é um estudo prático que pode ser utilizado para gestão de reservatórios e represas voltados para fins recreativos.

Visto que o balneário municipal de Quatá apresentou alto nível de trofia, conclui-se que o reservatório necessita de melhor fiscalização e 
cobrança de autoridades local para acompanhamento e controle de qualidade, visto que dentro dos critérios de classificação do IET ainda existe a possibilidade de evoluir para nível hipereutrófico, estágio este que compromete até mesmo fauna e flora local.

\section{REFERÊNCIAS}

ANA (Agência Nacional de Águas). Indicadores de qualidade: índice do estado trófico (IET). 2014. Disponível em http:// portalpnqa.gov.br/indicadores-estadotrofico.aspx. Acesso em: 04 ago 2018.

CARLSON, Robert E. A trophic state index for lakes1. Limnology and oceanography, v. 22, n. 2, p. 361-369, 1977. https://doi.org/10.4319/lo.1977.22.2.0361

CETESB- COMPANHIA AMBIENTAL DO ESTADO DE SÃO PAULO. Relatório de Qualidade das Águas Interiores no Estado de São Paulo: 2006. São Paulo: CETESB, 2007. (Série Relatórios)

CETESB - COMPANHIA AMBIENTAL DO ESTADO DE SÃO PAULO. Indicadores de Qualidade - Índice do Estado Trófico (IET). São Paulo: CETESB, 2013.

DONADIO, N. M. M.; GALBIATTI, J. A.; PAULA, R. C. de. Qualidade da água de nascentes com diferentes usos do solo na bacia hidrográfica do Córrego Rico, São Paulo, Brasil. Engenharia Agrícola, v. 25, n. 1, p. 115-125, 2005. https://doi.org/10.1590/S0100$\underline{69162005000100013}$

ESTEVES, F.A. Fundamentos de Limnologia. Rio de Janeiro: Editora Interciência, 1988. 574p.

FEDERATION, Water Environmental et al. Standard methods for the examination of water and wastewater. American Public Health Association (APHA): Washington, DC, USA, 2005.

HADLICH, G. M.; SCHEIBE, L. F. Dinâmica físicoquímica de águas superficiais em região de intensa criação de suínos: exemplo da bacia hidrográfica do rio Coruja-Bonito, município de Braço do Norte, SC. Geochimica Brasiliensis, v. 21, n. 3, 2012.

LAMPARELLI , M. C. Grau de trofia em corpos d'água do estado de São Paulo: avaliação dos métodos de monitoramento. São Paulo : USP/ Departamento de Ecologia, 2004. 235 f. Tese de doutorado, Universidade de São Paulo, 2004.

NETO, M. L. F.; FERREIRA, A. P. - Perspectivas da Sustentabilidade Ambiental Diante da Contaminação Química da Água: Desafios Normativos - Revista de Gestão Integrada em Saúde do Trabalho e Meio Ambiente - v. 2, n. 4, Seção 1, ago 2007.

PIVELI, R. P.; KATO, M. T. Qualidade das águas e poluição: aspectos físico-químicos. In: Qualidade das águas e poluição: aspectos físico-químicos. ABES, 2006.

SILVA, Í. et al. Qualidade de água na irrigação. Agropecuária Científica no Semiárido, v. 7, n. 03, p. 01-15, 2011.

SMITH, V. H.; SCHINDLER, D. W. Eutrophication science: where do we go from here? Trends. Ecology and Evolution, v. 24, p. 201-207, 2009. https://doi.org/10.1016/j.tree.2008.11.009

TOLEDO JR, A. P. Informe preliminar sobre os estudos para a obtenção de um índice para a avaliação do estado trófico de reservatórios de regiões quentes tropicais. São Paulo: CETESB, p. $12,1990$. 